\title{
Progression of right ventricular dilation in repaired tetralogy of fallot
}

\author{
Sujatha Buddhe*, Amee Shah, Wyman W Lai \\ From 16th Annual SCMR Scientific Sessions \\ San Francisco, CA, USA. 31 January - 3 February 2013
}

\section{Background}

Right ventricular (RV) dilation shown by cardiac MRI (CMR) is important for determining the timing of pulmonary valve replacement (PVR) in patients with repaired Tetralogy of Fallot (TOF). There is little known about the rate of progression (ROP) of RV dilation and factors that may affect ROP.

\section{Methods}

This is a retrospective cohort study of repaired TOF patients from 01/2004 to 09/2012. All children and young adults with at least two CMR's prior to PVR were included in the study. The ROP of RV dilation prior to PVR was calculated as the difference between the first and last CMRderived RV indexed end-diastolic volumes (iEDV) divided by the difference in time between the two studies. Subjects were divided into two groups based on the ROP of RV dilation: Group I - subjects with the most rapid ROP (defined as the top quartile of ROP) and Group II - all other subjects (the lower three quartiles of ROP). The differences in characteristic between groups were analyzed.

\section{Results}

A total of 63 subjects with repaired TOF were included in the study, including $30 \%$ with a history of pulmonary atresia and $19 \%$ with absent pulmonary valve. TOF repair included a transannular patch in 55\%, no patch in $16 \%$, and a conduit in $29 \%$. The mean age was $17.9 \pm 9.6$ years, and mean duration between CMR's was $3.4 \pm 2.0$ years. Median ROP for RV iEDV was 2.2 (range -14.4 to 35.8 ) $\mathrm{ml} / \mathrm{m} 2 /$ year.

On logistic regression analysis, RV iESV was the only independent predictor of significant ROP of RV dilation. ROC analysis showed an area under the curve of 0.75 (p<0.01). A RV iESV of $54 \mathrm{ml} / \mathrm{m} 2$ had $88 \%$ sensitivity and

$53 \%$ specificity in predicting significant ROP, while a cutoff of $67 \mathrm{ml} / \mathrm{m} 2$ had $69 \%$ sensitivity and $75 \%$ specificity.

\section{Conclusions}

There was no significant change in RV iEDV in a majority of repaired TOF subjects. RV iESV was the best predictor of more rapid RV dilation (greater ROP of RV iEDV). Additional studies are needed to better evaluate factors associated with more rapid ROP in repaired TOF.

\section{Funding}

None.

Table 1 Group Characteristics:

\begin{tabular}{|c|c|c|c|}
\hline Variables & Group I $(n=16)$ & Group $\|(n=47)$ & $\begin{array}{c}\mathrm{p}- \\
\text { value }\end{array}$ \\
\hline $\mathrm{ROP}(\mathrm{ml} / \mathrm{m} 2 / \text { year })^{\circ}$ & $\begin{array}{l}13.8(5.6 \text { to } \\
35.8)\end{array}$ & $\begin{array}{c}1.2(-14.5 \text { to } \\
5.4)\end{array}$ & $<0.01$ \\
\hline Age (years) * & $17.3 \pm 10.3$ & $18.1 \pm 9.4$ & 0.8 \\
\hline Male gender $\Phi$ & $12(75 \%)$ & $23(50 \%)$ & 0.09 \\
\hline RV iEDV * & $153 \pm 49$ & $124 \pm 31$ & 0.04 \\
\hline RV iESV * & $77 \pm 29$ & $56 \pm 19$ & 0.01 \\
\hline RV EF * & $50 \pm 7$ & $56 \pm 7$ & 0.01 \\
\hline LV iEDV * & $74 \pm 10$ & $78 \pm 15$ & 0.4 \\
\hline PR (moderate to severe) $\Phi$ & $14(88 \%)$ & $39(83 \%)$ & 0.4 \\
\hline PS (mild+) $\Phi$ & $3(19 \%)$ & 14(30\%) & 0.2 \\
\hline $\begin{array}{l}\text { RV outflow tract aneurysm } \\
\qquad \Phi\end{array}$ & $3(19 \%)$ & $13(28 \%)$ & 0.7 \\
\hline QRS duration (ms) * & $144 \pm 28$ & $140 \pm 27$ & 0.7 \\
\hline Age at surgery (years) ${ }^{\circ}$ & 0.7 (0.1 to 9.0$)$ & $1.5(0.0$ to 7.5$)$ & 0.4 \\
\hline Time since surgery (years) * & $15.1 \pm 8.8$ & $14.5 \pm 7.2$ & 0.8 \\
\hline $\begin{array}{c}\text { Time between CMR's (years) } \\
*\end{array}$ & $2.2 \pm 1.9$ & $3.8 \pm 1.9$ & $<0.01$ \\
\hline
\end{tabular}

${ }^{*}$ Mean $\pm \mathrm{SD}{ }^{\circ}$ Median (range) ; $\Phi$ Number (percentage) Abbreviations: EF ejection fraction, iESV - indexed end-systolic volume, LV - left ventricle, PR pulmonary regurgitation, PS - pulmonary stenosis, TR - tricuspid regurgitation 
- Convenient online submission

- Thorough peer review

- No space constraints or color figure charges

- Immediate publication on acceptance

- Inclusion in PubMed, CAS, Scopus and Google Scholar

- Research which is freely available for redistribution 